\title{
Proapoptotic signalling through Toll-like receptor-3 involves TRIF-dependent activation of caspase- 8 and is under the control of inhibitor of apoptosis proteins in melanoma cells
}

\author{
A Weber ${ }^{1,4,5}$, Z Kirejczyk ${ }^{1,5}$, R Besch ${ }^{2}$, S Potthoff ${ }^{1}$, M Leverkus $^{3}$ and G Häcker ${ }^{\star, 4}$
}

Toll-like receptor-3 (TLR3), a member of an immune recognition receptor family, is widely expressed in tumour cells and has been shown previously to have the capacity to not only activate immune signalling pathways, but also to exert proapoptotic activity in some cells. We show here that HaCaT human keratinocytes are susceptible to apoptosis induction by the TLR3 ligand poly I:C, and use these cells as a model to analyse the apoptotic signalling pathway. Although the BH3-only protein Noxa was transcriptionally induced by poly I:C and translocated to mitochondria, RNAi experiments showed that the BH3-only proteins Noxa, Bim and Puma were individually dispensable for poly I:C-induced apoptosis. Instead, poly I:C-induced activation of caspase-8 via TLR3 and its adapter TRIF was required for apoptosis. In human melanoma cell lines poly I:C failed to induce apoptosis unless protein synthesis was blocked. Significantly, sensitisation towards poly I:C-dependent caspase-8 activation and apoptosis in melanoma cells was also achieved by the synthetic Smac mimetic/inhibitor of apoptosis protein (IAP) antagonist, LBW242, or by specific downregulation of cIAP1 by siRNA. Inactivation of caspase-8 by CrmA overexpression reduced poly I:C/LBW242-induced apoptosis. These results indicate that the proapoptotic activity of TLR3/TRIF/caspase-8 in melanoma cells is under the control of IAPs, and the use of novel Smac mimetics might be a feasible approach to target melanoma.

Cell Death and Differentiation (2010) 17, 942-951; doi:10.1038/cdd.2009.190; published online 18 December 2009

Apoptosis results when a specialised signalling pathway is activated, and this signal pathway intersects with many pathways of immune activation or cell differentiation. TLRs are important sensors of especially microbial molecules and can recognise diverse components from infectious agents such as double-stranded RNA (TLR3), bacterial LPS (TLR4), lipopeptides (TLR2), microbial DNA (TLR9) and viral RNA (TLR7/8). ${ }^{1}$ Although TLRs are best known for their ability to initiate innate immune response and drive the stimulation of the adaptive immune response, their principal capacity to signal apoptosis has also been described. Some of the 10 known TLRs (such as TLR2 or 7) use the cytosolic protein MyD88 exclusively as a signal-transducing adapter. TLR3 instead uses the protein TRIF, while TLR4 can signal through both MyD88 and TRIF. Although initial description of apoptosis through TLR demonstrated this activity for
TLR2, ${ }^{2,3}$ later studies suggest that only TRIF but not MyD88 can signal apoptosis. ${ }^{4}$ In macrophages, these TRIF-using receptors can induce apoptosis only if NF- $\kappa \mathrm{B}$ is inhibited at the same time. ${ }^{4}$ With their capacity to induce apoptosis and activate the immune system, TLR agonists are an attractive therapeutic option for treatment of infectious and malignant disease. ${ }^{5}$

Apoptosis usually involves the activation of caspases through one of two upstream pathways. ${ }^{6}$ One (the extrinsic pathway) is triggered at the cell surface by death receptors and uses the protease caspase- 8 to activate the effector caspase-3 or to activate Bax/Bak via caspase-8-dependent cleavage of the BH3-only protein Bid. The other pathway, known as the intrinsic, mitochondrial or Bcl-2-regulated pathway, involves the release of mitochondrial cytochrome $c$ into the cytosol, which causes the activation of caspases

Institute for Medical Microbiology, Immunology and Hygiene, Technische Universität München, Munich, Germany; ${ }^{2}$ Department of Dermatology and Allergology, Ludwig-Maximilian University, Munich 80337, Germany; ${ }^{3}$ Otto-von-Guericke-Universität Magdeburg, Medizinische Fakultät, Universitätsklinik für Dermatologie und Venerologie, Magdeburg, Germany and ${ }^{4}$ Institute of Medical Microbiology and Hygiene, University Freiburg, Freiburg, Germany

*Corresponding author: G Häcker, Institute of Medical Microbiology, Technische Universität, Hermann Herder-Strasse 11, Trogerstrasse 30, Munich D-79104, Germany. Tel: + 49761203 6532; Fax: + 49761203 6651; E-mail: georg.haecker@uniklinik-freiburg.de

${ }^{5}$ These authors contributed equally to this work.

Keywords: apoptosis; Noxa; Bim; TLR3; TRIF; caspase-8

Abbreviations: Bak, Bcl-2 homologous antagonist/killer; Bax, Bcl-2associated X protein; Bcl-2, B-cell lymphoma protein 2; Bcl-XL, Bcl-2-like protein 1; Bid, BH3 interacting domain death agonist; Bim, Bcl-2-like protein 11; CIAP1/2, cellular IAP1,2; CHX, cycloheximide; CrmA, caspase-8 inhibitor from cowpox virus; DISC, deathinducing signaling complex, ; FLIP, CASP8 and FADD-like apoptosis regulator; GAPDH, Glyceraldehyde 3-phosphate dehydrogenase; IAP, inhibitor of apoptosis protein; IFN, interferon; IL-8, interleukin 8; MyD88, myeloid differentiation primary response protein-88; Mcl-1, induced myeloid leukemia cell differentiation protein; Noxa, phorbol-12-myristate-13-acetate-induced protein 1; PI, propidium iodide; poly I:C/pIC, polyinosinic:polycytidylic acid; Puma, p53 upregulated modulator of apoptosis; p53, tumor protein 53; TLR, Toll-like receptors; TNF, tumor necrosis factor; TRADD, tumor necrosis factor receptor type 1-associated death domain protein; TRAF6, TNF receptor associated factor family protein 6; TRIF, TIR-domain-containing adapter-inducing interferon (IFN); XIAP, X-linked inhibitor of apoptosis protein; zVAD-fmk, (carbobenzoxy-valyl-alanyl-aspartyl-[0-methyl]- fluoromethylketone)

Received 27.4.09; revised 22.10.09; accepted 09.11.09; Edited by F Madeo; published online 18.12.09 
through a large protein complex. In the mitochondrial pathway, the proteins of the $\mathrm{Bcl}-2$ family are critical regulators. The BH3-only-subfamily proteins (for instance Bim, Puma, Noxa) act as triggers that activate the effectors of cytochrome $c$ release, Bax and Bak. This activation can be blocked by inhibitors of the Bcl-2 family such as Bcl-2, Bcl- $x_{\mathrm{L}}$ and $\mathrm{Mcl}-1$. . $^{7,8}$

Disseminated melanoma is highly resistant to chemotherapy. To test the possibility of new molecular approaches to apoptosis induction in melanoma, we explored the capacity of TLR3 to activate the components of the apoptotic machinery. It has recently been demonstrated that the synthetic ligand of TLR3, poly I:C, causes upregulation of Noxa and apoptosis in a number of human tumour cell lines. ${ }^{9}$ TLR3 is expressed in many human tumour cells ${ }^{10-12}$ and although a proapoptotic effect of poly I:C in cancer cells has been shown, this requires additional stimuli, such as IFN treatment or inhibition of protein synthesis, in most tumour cells. ${ }^{10,12}$ We found very little apoptosis induction by poly $\mathrm{I}: \mathrm{C}$ alone in a panel of human melanoma cell lines although poly I:C could induce apoptosis in the presence of the inhibitor of protein synthesis, $\mathrm{CHX}$. However, $\mathrm{HaCaT}$ human keratinocytes were highly sensitive to apoptosis induction by poly I:C. To delineate the apoptotic signalling pathway without the confounding effects of $\mathrm{CHX}$, we first analysed $\mathrm{HaCaT}$ cells. The BH3-only protein Noxa was strongly upregulated by poly $\mathrm{I}: \mathrm{C}$ in $\mathrm{HaCaT}$ cells. However, Noxa was dispensable for apoptosis induction by poly $\mathrm{I}: \mathrm{C}$, which used components of the death receptor signalling pathway to activate caspases. In melanoma cells, this pathway was triggered by poly $\mathrm{I}: \mathrm{C}$ in the presence of $\mathrm{CHX}$ or when the cellular IAPs were pharmacologically inhibited. TLR3 thus can trigger a proapoptotic pathway in melanoma cells whose potency can be strongly enhanced by novel inhibitors of IAPS.

\section{Results}

We first tested a panel of four human melanoma-derived cell lines for apoptosis induction by poly I:C. Very little apoptosis was observed with concentrations up to $50 \mu \mathrm{g} / \mathrm{ml}$. However, HaCaT human keratinocytes were sensitive to treatment with poly $\mathrm{I}: \mathrm{C}$ at various doses (Figure $1 \mathrm{a}$ and Supplementary Figure S1A). Although all melanoma lines expressed TLR3 mRNA at clearly detectable levels (Supplementary Figure $\mathrm{S1C})$, they only became sensitive for poly $\mathrm{I}: \mathrm{C}$-induced apoptosis when protein synthesis was simultaneously blocked by the addition of $\mathrm{CHX}$, suggesting that an unstable inhibitor of poly I:C-induced apoptosis was expressed in melanoma cells that had to be degraded before apoptosis was induced (Figure 1b and Supplementary Figure S1B). Cell death could be blocked by the broad caspase inhibitor zVADfmk (Figure 1b and Supplementary Figure S1A). As $\mathrm{CHX}$ might confound pathway analysis, we decided to focus first on the pathway to apoptosis in HaCaT cells.

Both mitochondrial pathway (in this case mediated by the BH3-only protein Noxa) and a pathway involving caspase-8 have been implicated in poly I:C-induced apoptosis. Noxa protein was strongly induced in $\mathrm{HaCaT}$ cells upon treatment with poly $\mathrm{I}: \mathrm{C}$, while levels of the $\mathrm{BH}$-only proteins $\mathrm{Bim}$ and Puma were not substantially altered (Bim expression even seemed to be slightly reduced; Figure 1c). Induction of Noxa was blocked by the inhibitor of protein synthesis $\mathrm{CHX}$ (Supplementary Figure S1D). Induction of type-I IFN (IFN-I) is a well-known function of TLR3, and noxa has been described as an IFN-I-response gene. ${ }^{9}$ RNAi against the IFN-I receptor blocked the induction of Noxa by poly I:C (Supplementary Figure S1E). Noxa was found almost exclusively in the mitochondrial fraction of poly I:C-stimulated $\mathrm{HaCaT}$ cells (Supplementary Figure S1F). These data suggested that poly I:C triggered the mitochondrial apoptosis pathway through IFN-I-mediated upregulation of Noxa, and we turned to a more detailed analysis of this pathway.

Poly I:C activated Bax, as measured by staining for active Bax (using an antibody that only binds to Bax if it has undergone a conformational change seen during activation; Figure 2a). However, this activation was almost completely blocked by a caspase inhibitor (Figure 2a). This indicated that the mitochondrial pathway was activated but subsequently to caspase activation. It is known that Bax can be activated by caspase-8-dependent cleavage of Bid to its active form tBid. Indeed, poly $\mathrm{I}: \mathrm{C}$ induced the proteolytic processing of caspase-8 over time as well as cleavage of the caspase-8 substrate Bid (Figure $2 \mathrm{~b}$ and $\mathrm{c}$ ).

Together, these data showed that poly I:C treatment of HaCaT cells activated two probably separate apoptotic pathways, namely a mitochondrial pathway involving upregulation of Noxa and a pathway involving caspase-8. Caspase-8 can induce apoptosis via Bid cleavage and mitochondrial activation, but may also circumvent mitochondria by direct activation of caspase-3, depending on the cell type. ${ }^{13}$ We next used RNAi against a number of candidate signalling proteins to define the pathway. HaCaT cell lines stably expressing shRNA directed against Noxa or Bim were treated with poly I:C. However, downregulation of either of these proteins (Figure 3a) failed to protect the cells. Since blockade of Noxa expression upon poly I:C treatment by the shRNA was not complete (Supplementary Figure S2A), we also used transient transfection of Noxa-specific siRNA. This strategy on its own surprisingly induced some cell death. Knockdown of Noxa was very efficient (Supplementary Figure S2B) yet failed to protect against cell death induced by poly $\mathrm{I}: \mathrm{C}$ (Figure 3b). Likewise, transient knockdown of Bid or Puma by siRNA had no effect (Figure 3b; for knockdown efficiency see Supplementary Figure S2B, C). Note that apoptosis induction was not impaired by IFNAR1 knockdown, although poly I:C-dependent upregulation of Noxa was prevented (Supplementary Figure S1E, and data not shown). We further used HaCaT cells overexpressing Bcl-2 to test for the importance of the mitochondrial pathway. As shown in Supplementary Figure S3, transgenic Bcl-2 failed to protect against poly $\mathrm{I}: \mathrm{C}$-induced apoptosis while protecting, as expected, against apoptosis induced by UV light. Taken together, these data strongly suggest that although some components of the mitochondrial pathway are activated by poly I:C in HaCaT cells, this pathway is dispensable for this form of apoptosis.

We next tested the hypothesis that poly I:C activated caspase- 8 through TLR3. TLR3 is an endosomal receptor that signals when its ligand is taken up in endosomes into the cell. ${ }^{14}$ Maturation of endosomes can be blocked by the inhibitor of endosomal ATPase, bafilomycin-A. Accordingly, 


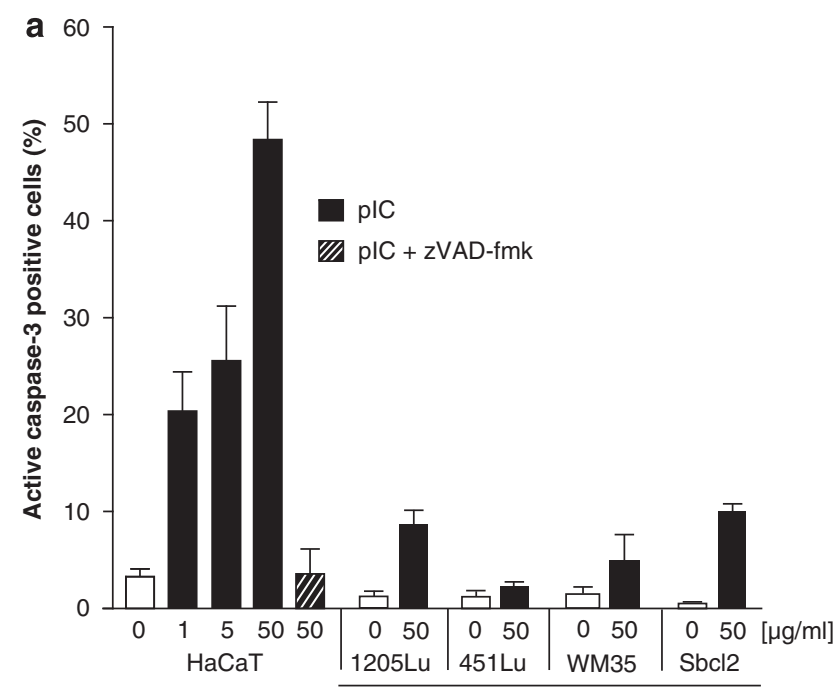

Melanoma

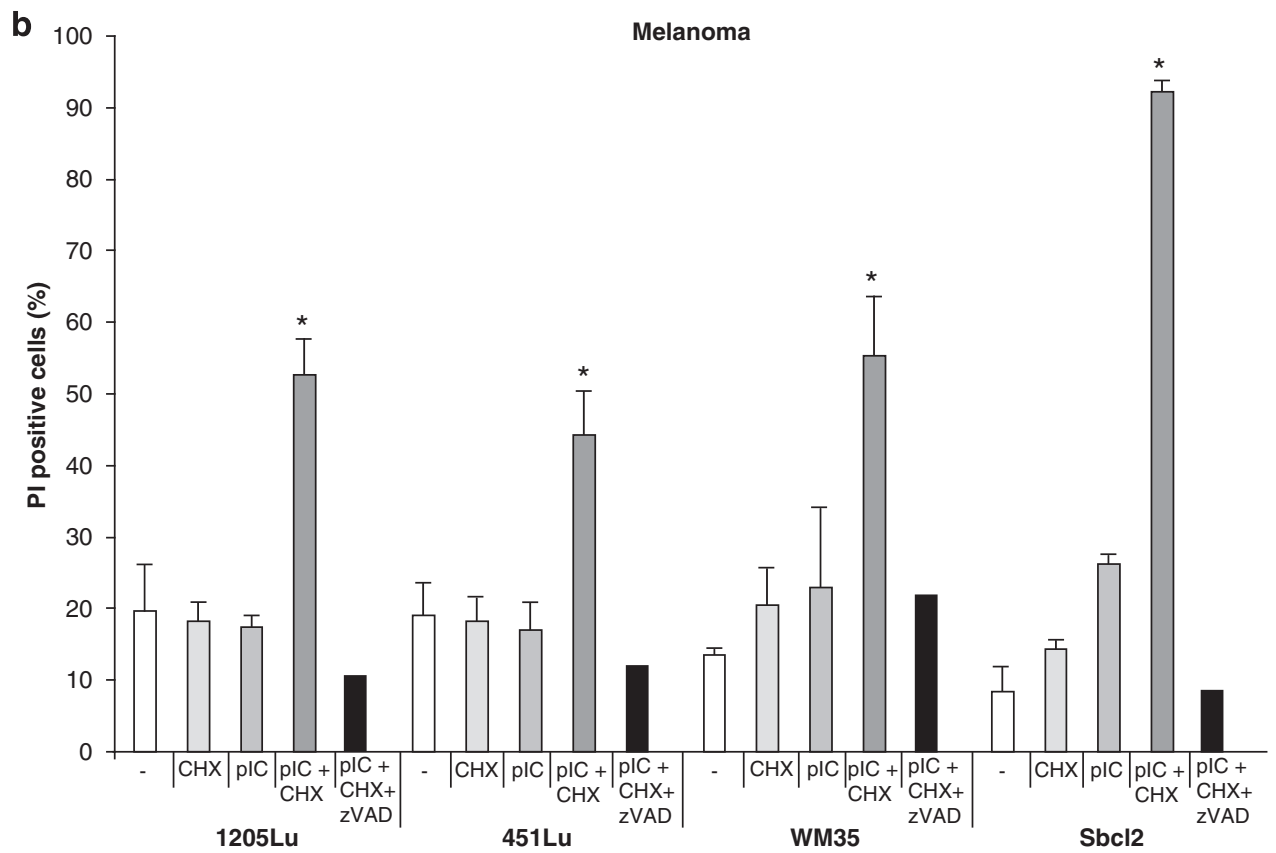

C

$\mathrm{HaCaT}$

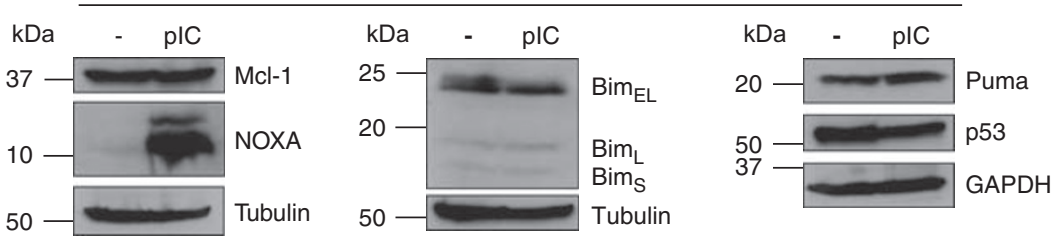

Figure 1 Induction of apoptosis in HaCaT keratinocytes and human melanoma cell lines during poly I:C treatment. (a) Cells were left untreated or treated with varying concentrations of poly l:C (pIC) for $24 \mathrm{~h}$ and cell death was assayed by staining for active caspase-3, followed by flow-cytometric analysis. A $50-\mu \mathrm{M}$ concentration of zVAD-fmk was added $20 \mathrm{~min}$ before addition of the maximum concentrations of $\mathrm{pIC}$ used. Data represent means \pm S.E.M. of three experiments. (b) Melanoma cells were either left untreated (-) or treated with $\mathrm{CHX}(2.5 \mu \mathrm{g} / \mathrm{ml})$, poly I:C $(50 \mu \mathrm{g} / \mathrm{ml})$ or poly I:C plus $\mathrm{CHX}$ for $24 \mathrm{~h}$, followed by PI staining and FACS analysis. CHX and zVAD-fmk was added $2.5 \mathrm{~h}$ prior to stimulation with poly I:C. Data represent means \pm S.E.M. of three experiments. The ZVAD-fmk experiments represent the mean values of two experiments. ${ }^{*} P<0.05$ compared with cells treated solely with $\mathrm{CHX}$ or poly I:C. (c) Western blot analysis of whole-cell lysates showing levels of Bim, Noxa, Puma and Mcl- 1 expression in $\mathrm{HaCaT}$ keratinocytes left untreated or treated with polyl:C for $24 \mathrm{~h}$. The immunoblots show representative results from three independent experiments

poly I:C-induced apoptosis in HaCaT was inhibited by bafilomycin-A (Supplementary Figure S1B). Knockdown of either TLR3 or its signalling adapter, TRIF, significantly reduced cell death induction by poly $\mathrm{I}: \mathrm{C}$ in $\mathrm{HaCaT}$ cells (Figure $3 b$ ). In good accordance with the results of the cell death assays (Figure 3b), knockdown of TLR3 and TRIF 
reduced the activation of caspase- 8 and caspase- 3 while Puma-specific siRNA did not (Figure $3 c$ ). There was no change in caspase- 8 processing, but a slight reduction in caspase-3 cleavage when Bid was knocked down, although no reduction in cell death was seen. Most likely, there is some additional caspase- 3 activation via Bid and the mitochondrial pathway, but this is not relevant as sufficient caspase- 3 is activated also without mitochondrial contribution.
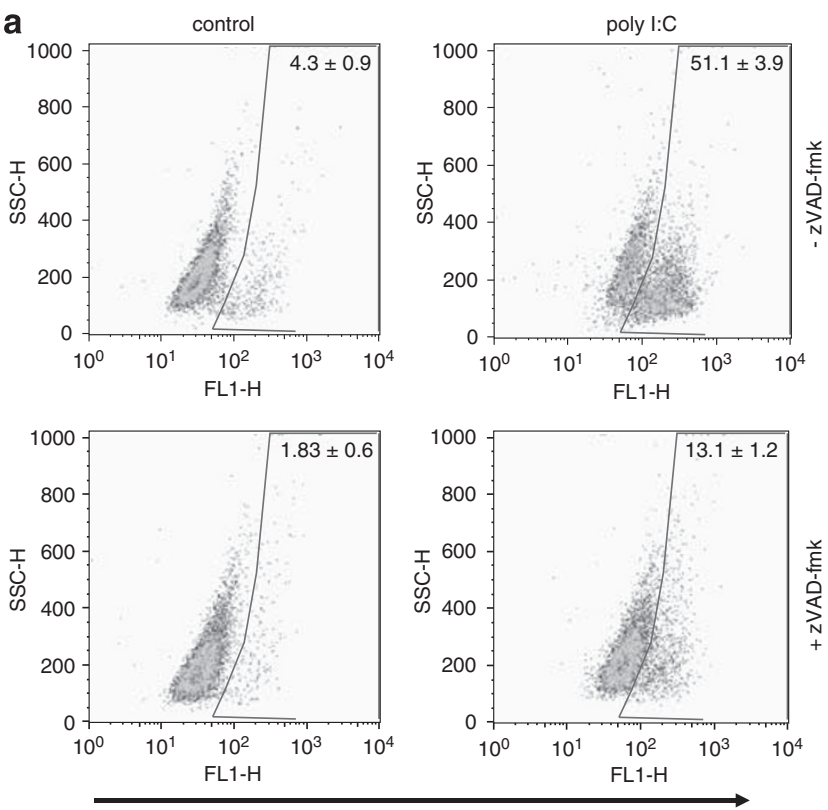

active Bax

b

$+\mathrm{pIC}$

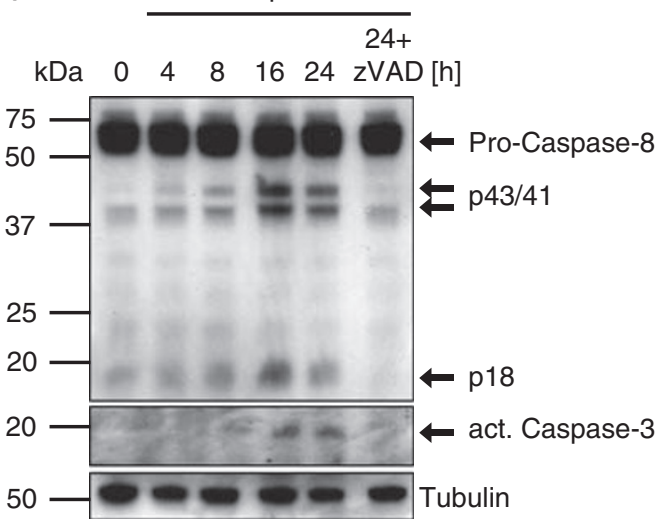

C

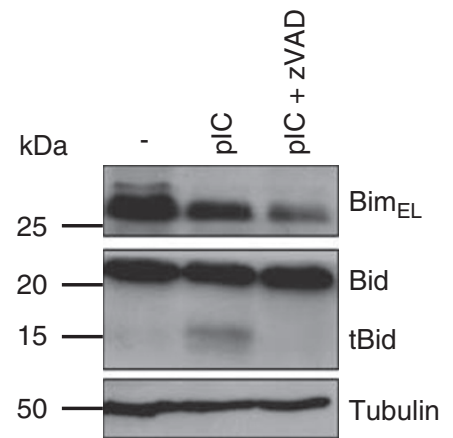

Importantly, knockdown of caspase- 8 by siRNA also clearly reduced cell death and activation of caspase- $8 / 3$ induced by poly I:C (Figure $3 \mathrm{~b}$ and $\mathrm{c}$; for knockdown efficiency see Supplementary Figure S2B, C). Poly I:C treatment of HaCaT cells thus activates proapoptotic pathways that encompass Noxa induction, caspase-dependent cleavage of Bid and activation of Bax. However, the signalling pathway that is relevant to induction of cell death involves endosomal uptake of poly I:C, signalling through TLR3 and TRIF, and activation of caspase-8.

As shown above, poly $\mathrm{I}: \mathrm{C}$ induced apoptosis in melanoma cells in the presence of $\mathrm{CHX}$. Poly I: $\mathrm{C} / \mathrm{CHX}$-induced apoptosis in melanoma cells was inhibited by bafilomycin-A, indicating poly I:C signalling through TLR3 (Supplementary Figure S1B). Treatment with poly $\mathrm{I}: \mathrm{C}$ but not $\mathrm{CHX}$ upregulated the expression of TLR3 in several melanoma cell lines (Supplementary Figure S1C). We proceeded to test whether caspase8 was also activated and was also required for proapoptotic signalling by poly $\mathrm{I}: \mathrm{C}$ in melanoma cells in the presence of $\mathrm{CHX}$. As shown in Supplementary Figure S4A, caspase-8 activation could be observed shortly after treatment with poly $\mathrm{I}: \mathrm{C} / \mathrm{CHX}$ in the tested melanoma cell lines (strongest in Sbcl2), whereas levels of $C F L I P_{L}$ did not change considerably. As shown in Figure 4a, caspase-8-specific RNAi clearly reduced cell death induced by poly I: $\mathrm{C} / \mathrm{CHX}$ in three melanoma lines. In one cell line, caspase-8-specific siRNA had no effect despite fairly efficient knockdown of the protein (Figure 4b); this lack of protection is consistent with only very moderate processing of caspase- 8 in this cell line (1205Lu; Supplementary Figure S4A). Nevertheless, poly I:C/CHX-induced cell death was blocked by adding zVAD-fmk in all melanoma cell lines (data not shown).

TLR3/TRIF therefore seemed to engage a proapoptotic pathway that was in melanoma cells controlled by some $\mathrm{CHX}$ sensitive protein. Recent evidence indicates that cellular IAPs (clAP1 and clAP2) are involved in the regulation of caspase-8 activation, at least downstream from tumour necrosis factor receptor-1(TNFR1). ${ }^{15,16}$ Both clAP1 and clAP2, and the related protein XIAP were expressed in the melanoma lines. Treatment with $\mathrm{CHX}$ induced some reduction in clAP1 protein (strongest in 451Lu and noticeable in most experiments on WM35, although only very moderately in $1205 \mathrm{Lu}$ ), whereas protein levels of XIAP and $\mathrm{CFLIP}_{\mathrm{L}}$ remained constant (Figure 4c and Supplementary Figure S4A).

This suggested that clAP-regulated activation of caspase-8 at least contributed to apoptosis induced by poly $\mathrm{l}: \mathrm{C} / \mathrm{CHX}$ in

Figure 2 Activation of Bax by poly I:C requires caspase activity. (a) Cells were left untreated or treated with poly I:C $(50 \mu \mathrm{g} / \mathrm{ml})$ for $24 \mathrm{~h}$ and Bax activation was monitored by flow cytometry after staining with anti-active Bax/FITC-conjugated goat anti-mouse IgG. ZVAD-fmk ( $50 \mu \mathrm{M})$ was added alone or 20 min before addition of poly I:C. Representative dot blots are shown. Values represent \pm S.E.M. of five independent experiments. Poly I:C treatment of $\mathrm{HaCaT}$ keratinocytes leads to cleavage of caspase-8, Bid and increased amounts of active caspase-3. (b) Immunoblot showing kinetics of pro-caspase-8 cleavage and induction of active caspase-3 after treatment with poly I:C (pIC, $50 \mu \mathrm{g} / \mathrm{ml})$. The cleavage products of pro-caspase-8 are marked p43/41 and p18. (c) Immunoblot showing cleavage of Bid $24 \mathrm{~h}$ post stimulation with poly I:C (pIC, $50 \mu \mathrm{g} / \mathrm{ml}$ ) pretreated with $\mathrm{zVAD}$-fmk (zVAD, $50 \mu \mathrm{M}$ ) for $20 \mathrm{~min}$ or not treated. Tubulin was used as a loading control. The immunoblots are representative of two independent experiments 

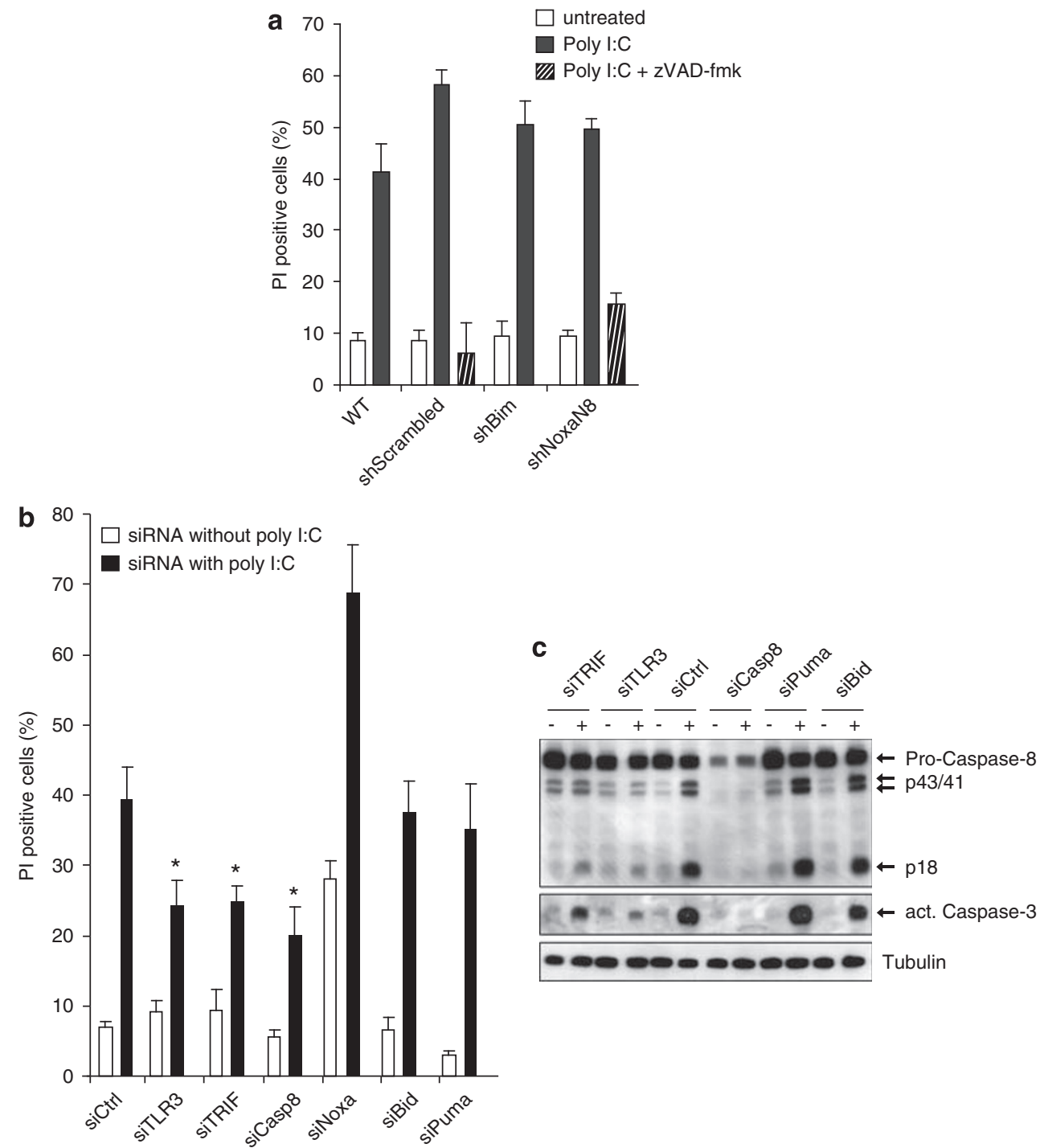

Figure 3 TLR3, TRIF and caspase-8, but neither Noxa nor Bim knockdown by RNAi, protects HaCaT cells against cell death induced by poly I:C. (a) HaCaT wild-type cells (WT) and cell lines expressing shRNA specific for Noxa or Bim, or a control shRNA (scrambled anti-Bim sequence) were treated for $24 \mathrm{~h}$ with $50 \mu \mathrm{g} / \mathrm{ml}$ poly I:C or not treated, and cell death was assessed by staining with PI followed by flow-cytometric analysis. HaCaT shScrambled control and shNoxaN8 were treated with $50 \mu \mathrm{M}$ zVAD-fmk prior to stimulation with poly I:C. Data represent means \pm S.E.M. of at least four experiments. (b) Cells were transiently transfected with control (Ctrl), Noxa, Bid, Puma, TLR3, TRIF or caspase-8-specific siRNAs. Forty-eight hours post transfection, cells were treated with $50 \mu \mathrm{g} / \mathrm{ml}$ poly I:C for $24 \mathrm{~h}$ as indicated and assayed for PI-positive cells. Data represent means \pm S.E.M. of at least three independent experiments. ${ }^{*} P<0.04$ compared with control siRNA plus poly I:C. In two independently performed experiments using siCtrl or siNoxa, increased PI staining could be blocked by adding $50 \mu \mathrm{M}$ z-VAD-fmk prior to treatment with poly I:C (data not shown). (c) Western blot showing caspase-8 activation and induction of active caspase-3 in the siRNA conditions described in panel $\mathbf{b}$.

melanoma lines (although there appear to be other pathways that may be activated by this treatment in some cells, as suggested by the results obtained with the 1205Lu line). The recent development of IAP antagonists/Smac mimetics makes it possible to investigate this checkpoint. These inhibitors cause depletion of clAPs by the ubiquitin-proteasome system and induce the secretion of TNF in certain cell types. Upon clAP degradation, autocrine TNF secretion has been reported to efficiently induce apoptosis through its receptor TNFR1 in those cells. ${ }^{15,16}$ Further, there is evidence suggesting that TLR3/TRIF might use the signal transduction machinery of TNFR1. In particular, TNF-signalling molecules RIP and TRADD have been demonstrated to be also part of the TLR3-signalling machinery. ${ }^{17,18}$ Since our data show that poly I:C can, like TNFR1, activate caspase-8, we followed the hypothesis that clAPs may control TRIF-induced apoptosis in a manner similar to TNFR1-induced cell death. We used the Smac mimetic LBW242 to test for a role of clAPs in poly I:C-induced apoptosis. Melanoma lines and $\mathrm{HaCaT}$ cells expressed varying levels of CIAP1, ClAP2 and XIAP (Figure 5a). Treatment with LBW242 caused reduction in cIAP1 levels, while XIAP levels stayed constant and cIAP2 levels surprisingly increased after $24 \mathrm{~h}$ LBW242 treatment (Figure $5 \mathrm{a}$ and $\mathrm{b}$ ). Treatment of cell lines with a combination of poly I:C and LBW242 showed a strong synergistic, proapoptotic effect of the two compounds (Figure $5 \mathrm{c}$ ). In all 

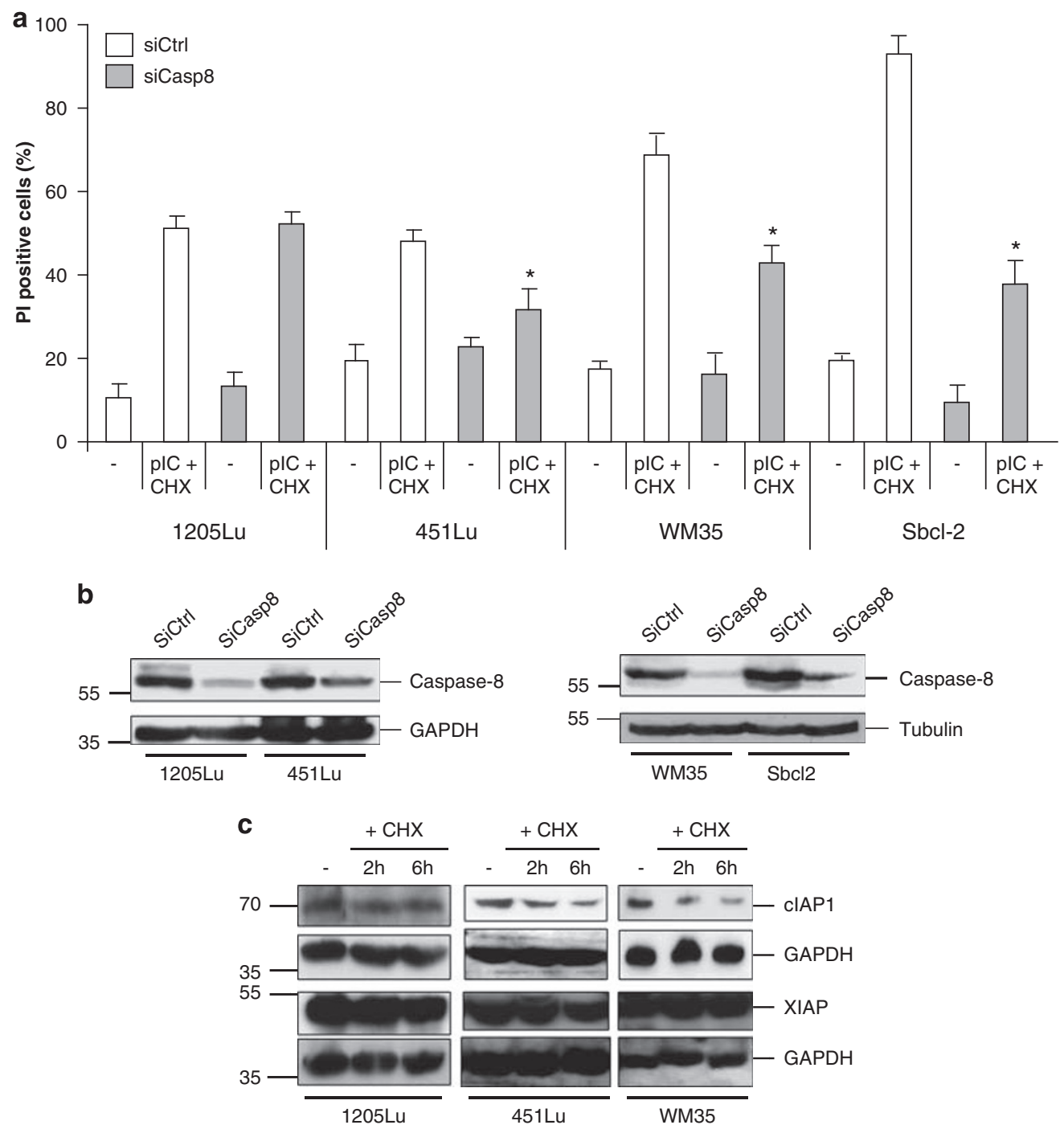

Figure 4 Protection of human melanoma cells against cell death induced by poly I:C/CHX by caspase-8 knockdown. (a) 1205Lu, 451Lu, WM35 and Sbcl2 human melanoma cells were transiently transfected with control (siCtrl) or caspase-8 (Casp8)-specific siRNA. Forty-eight hours post transfection, cells were left untreated (-) or pretreated $2.5 \mathrm{~h}$ with $\mathrm{CHX}$ followed by addition of $50 \mu \mathrm{g} / \mathrm{ml}$ poly I:C for $24 \mathrm{~h}$ as indicated and assayed for PI-positive cells. Data represent means \pm S.E.M. of at least three independent experiments. ${ }^{*} P<0.05$ compared with control siRNA plus poly l:C/CHX. Poly I:C/CHX-induced apoptosis could be blocked in all melanoma cell lines by zVADfmk (data not shown). (b) The same cells were lysed prior to stimulation and assayed for caspase-8 knockdown efficiency by Western blotting. GAPDH or tubulin was used as loading control. (c) Western blot of whole-cell lysates from 1205Lu, $451 \mathrm{Lu}$ and WM35 treated for $2 \mathrm{~h}$ or $6 \mathrm{~h}$ with cycloheximide $(2.5 \mu \mathrm{g} / \mathrm{ml})$. All Western blots are representative of two independent experiments

four melanoma lines tested, there was substantial overadditive induction of cell death; in two of the four lines this effect was massive (Figure $5 c$ ). The specific TLR3 ligand poly $A: U$ also induced cell death in the tested cell lines in combination with LBW242, supporting the concept of TLR3dependent signalling (Supplementary Figure S5). Again, induction of apoptosis by poly I:C/LBW242 was dependent on activation of caspase-8 (Figure $5 d$ and Supplementary Figure S4B) and presence of caspase-8, because caspase-8 knockdown by siRNA resulted in significant protection against poly I:C/LBW242-induced apoptosis (Figure 6a). Furthermore, overexpression of CrmA reduced LBW242-dependent sensitisation to poly $\mathrm{I}: \mathrm{C}$, confirming the importance for activation of caspase-8 (Supplementary Figure S6).

To confirm that clAP1 downregulation by LBW242 renders melanoma cells susceptible to poly $\mathrm{I} C \mathrm{C}$, we specifically targeted clAP1 by siRNA. As expected, this sensitised melanoma cells (cell line WM35 was used for these experiments) to poly I:C treatment alone (Figure $6 \mathrm{~b}$ ).

Since cFLIP is a well-known modulator of death-receptordependent caspase-8 activation, ${ }^{19}$ we also analysed cFLIP expression levels. These levels were only slightly altered during treatment of melanoma cells with poly I:C/LBW242 (Figure $5 \mathrm{~d}$ ), suggesting that a contribution from cFLIP was minor. cFLIP levels were slightly induced in two of the cell lines; since cFLIP is a well-known target of NF- $\kappa$ B activity, this increase may be a result of enhanced $\mathrm{NF}-\kappa \mathrm{B}$ signalling during treatment (see below). Interestingly, induction of FLIP $\mathrm{L}$ protein levels by poly I:C/LBW242 was predominantly found in the less responsive $1205 \mathrm{Lu}$ and $451 \mathrm{Lu}$ cell lines (compare cell death (Figure $5 \mathrm{c}$ ) and efficiency of caspase-8 activation and FLIP $\mathrm{P}_{\mathrm{L}}$ levels (Figure $5 \mathrm{~d}$ )). 

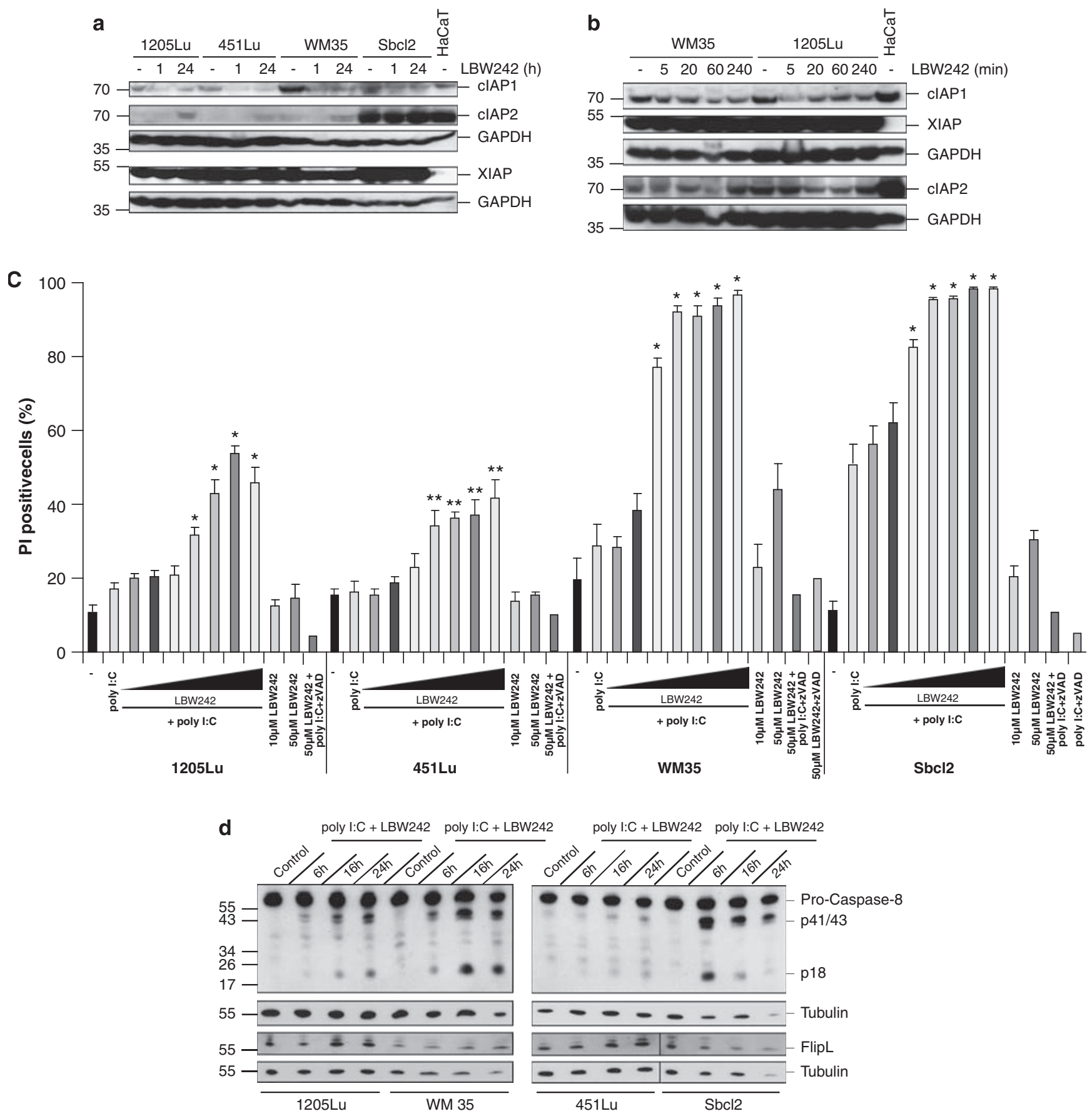

Figure 5 LBW242 reduces the levels of cIAP1 in melanoma and sensitises human melanoma cells to poly I:C-induced apoptosis. (a) 1205Lu, 451Lu, WM35 and Sbcl2 human melanoma cells were left untreated $(-)$ or treated with LBW242 $(10 \mu \mathrm{M})$ for 1 and $24 \mathrm{~h}$, and assayed for the presence of cIAP1, clAP2 and XIAP by Western blotting. GAPDH was used as loading control. Unstimulated HaCaTs were used for comparison. (b) Western blots of whole-cell extracts from 1205Lu and WM35 showing levels of CIAP1/2 and XIAP amounts before (-) and after stimulation with LBW242 $(10 \mu \mathrm{M})$ at earlier time points (5-240 min) in comparison with unstimulated HaCaT keratinocytes. All Western blots show representatives of two independent experiments. (c) Cell lines were incubated without or with the indicated drugs and assayed for PI-positive cells $72 \mathrm{~h}$ post stimulation by FACS analysis. LBW242 concentrations were 1, 10, $100 \mathrm{nM}$ and 1, 10,30,50 $\mu \mathrm{M}$. Data represent means \pm S.E.M. of at least three independent experiments. Experiments using zVAD-fmk represent the mean values of two experiments. ${ }^{*} P<0.006$; ${ }^{* *} P<0.03$ compared with cells treated with $50 \mu \mathrm{g} / \mathrm{ml}$ poly $\mathrm{l}: \mathrm{C}$ alone. (d) Western blots of whole-cell extracts from melanoma cells showing the cleavage products of pro-caspase-8 (marked p43/41 and p18) and cFLIP levels after treatment for different time points without (control) or with poly I:C $(50 \mu \mathrm{g} / \mathrm{ml})$ plus LBW242 $(10 \mu \mathrm{M})$. Note that poly I:C or LBW242 alone did not induce activation of caspase-8 (see Supplementary Figure S4B)

In susceptible tumour cells LBW242 (alone) induces apoptosis through NF- $\kappa \mathrm{B}$ activation and subsequent autocrine TNF-induced cell death. ${ }^{15}$ We detected the activation of an NF- $\kappa$ B-driven luciferase reporter gene in $1205 \mathrm{Lu}$ cells by single treatment with poly I:C or LBW (Supplementary Figure S7A). Using IL-8 mRNA transcription as a readout for NF- $\kappa \mathrm{B}$ 

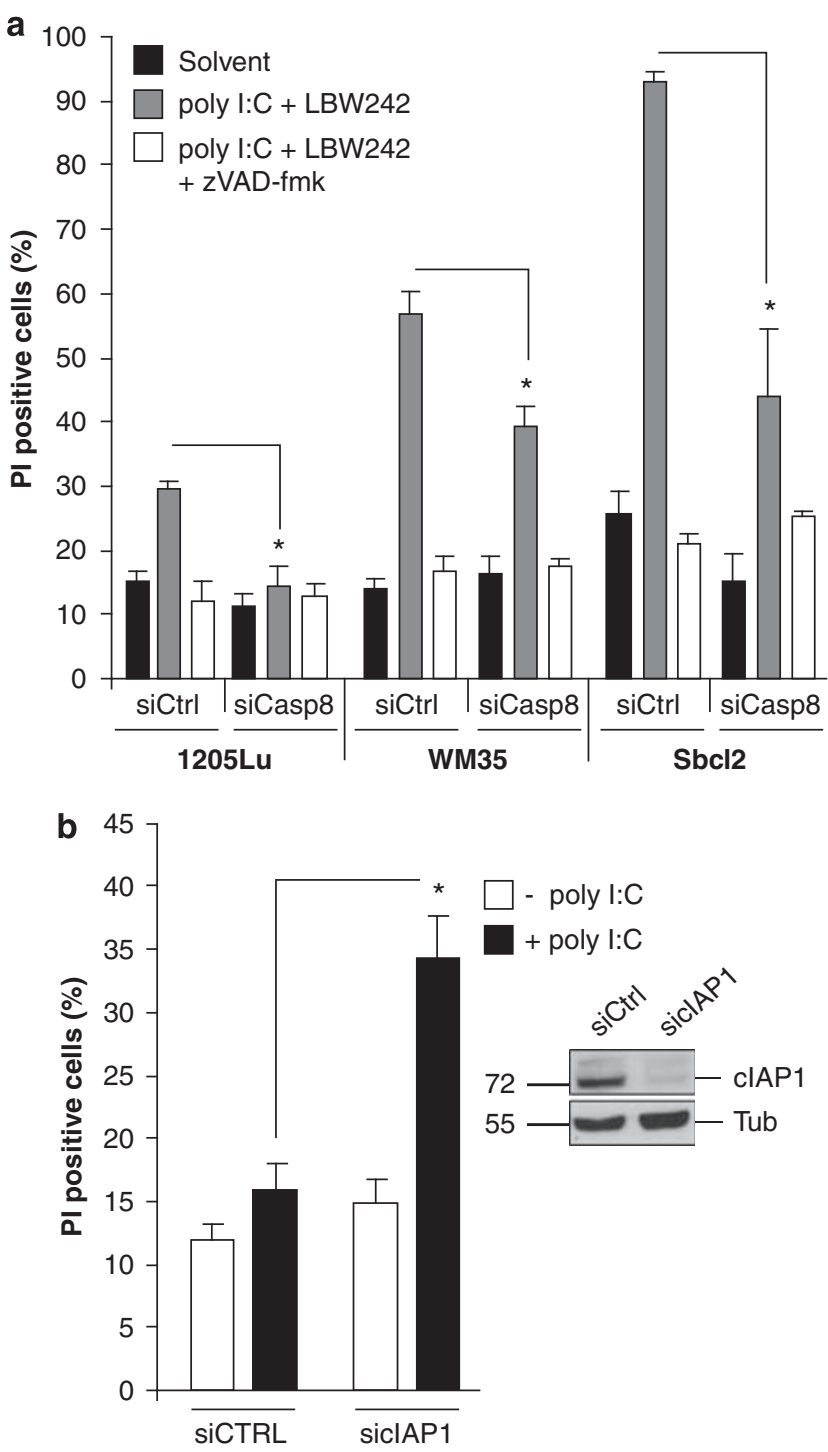

Figure 6 Caspase-8 knockdown by RNAi protects human melanoma cells against cell death induced by poly I:C/LBW242. (a) 1205Lu, WM35 and Sbcl2 human melanoma cells were transiently transfected with control (Ctrl) or caspase-8 (Casp8)-specific siRNA. Twenty-four hours post transfection, cells were treated with DMSO (solvent) or treated with poly I:C $(50 \mu \mathrm{g} / \mathrm{ml})+$ LBW242 $(10 \mu \mathrm{M})$ for $72 \mathrm{~h}$ and assayed for PI-positive cells. Data represent means \pm S.E.M. of at least three independent experiments. ${ }^{*} P<0.05$ compared with control siRNA plus poly I:C/ LBW242. Note that poly I:C/LBW242-induced apoptosis could be blocked in all melanoma cell lines by zVAD-fmk. (b) WM35 cells were transiently transfected with control (Ctrl) or clAP1-specific siRNA. Forty-eight hours post transfection, cells were left unstimulated or stimulated with poly I:C for $72 \mathrm{~h}$. Data represent the means \pm S.E.M. of three independent experiments. ${ }^{*} P<0.02$ compared with siCtrl cells treated with $50 \mu \mathrm{g} / \mathrm{ml}$ poly I:C. Inset: Western blot showing knockdown of cIAP1 after $48 \mathrm{~h}$

activation, we could detect IL-8 induction only using poly I:C but not LBW (Supplementary Figure S7B). As TLR3/TRIF normally, probably, causes the activation of canonical NF- $\kappa$ B1 signalling through TRAF $6,{ }^{20}$ while Smac mimetics activate non-canonical NF- $\kappa$ B2 signalling through $\mathrm{NIK},{ }^{15}$ this might reflect a differential activation of the IL-8 promoter. Importantly, no TNF was detectable in the supernatants of the four melanoma lines incubated in the presence of LBW242 $(10 \mu \mathrm{M})$ or poly I:C $(50 \mu \mathrm{g} / \mathrm{ml})$, alone or incubated with LBW242 plus poly I:C (detection limit was about $15 \mathrm{pg} / \mathrm{ml}$, data not shown). This strongly suggests that indeed clAPs operate to control the assembly of a death-inducing complex around the adapter molecule TRIF. Loss of cIAPs, which can be achieved by pharmacological Smac mimetics, sensitises the cells for poly $\mathrm{I}: \mathrm{C}$-induced apoptosis. This pathway uncovers an unexpected apoptosis susceptibility in otherwise extremely resistant melanoma cells, and holds promise for therapeutic targeting of disseminated melanoma.

\section{Discussion}

This study investigated signal transduction components in poly I:C-induced apoptosis. In HaCaT cells, poly I:C-induced apoptosis required endosomal uptake and engagement of TLR3, TRIF and caspase-8. Although elements of the mitochondrial pathway were activated, they were not essential for apoptosis. In human melanoma cells, efficient induction of apoptosis by poly I:C occurred only together with blockade of protein synthesis and then likewise proceeded through caspase-8. Melanoma cells were sensitised to apoptosis induction through poly I:C by the Smac mimetic LBW242.

TLRs are receptors for microbial ligands and serve to alert the cell and the immune system to the presence of infectious agents. They are most widely expressed on myeloid cells, but are also found on other cell types such as endothelium in a number of tissues. ${ }^{21}$ The expression pattern of the various TLRs varies considerably. TLR3 is found on a number of nonimmune cells where it may have functions in recognition of viruses that infect these cells directly. Apoptosis is an important defence mechanism against viral infection, ${ }^{22}$ and it is possible that widespread expression of TLR3 reflects this use of the receptor.

Apoptosis induction by poly I:C in tumour cells has been reported previously and has been found to depend on Noxadependent mitochondrial apoptosis. ${ }^{9}$ Although Noxa may contribute to this response in some cases, it was not required in HaCaT cells. TLRs can signal via one of two intracellular adapter molecules, MyD88 or TRIF. Available evidence suggests that TRIF but not MyD88, when engaged by TLRs, can induce apoptosis, , 4,23,24 and both TLR3 and TRIF were required for apoptosis induction in our study, as was caspase-8. During Fas death-receptor-induced apoptosis, caspase-8 is recruited into a complex termed DISC, whose main components are FADD, cFLIP and caspase- $8 ;^{25}$ in the case of TNFinduced apoptosis, this also includes the adapter protein TRADD. ${ }^{26}$ TRIF can trigger a number of signalling responses, notably induction of type-I IFN. A number of studies suggest that TRIF can in fact recruit or at least activate components of the death-receptor-family member TNFR1 signal transduction machinery, involving DISC components. This has been shown for the kinase RIP1 $1^{17,27}$ and most recently for the protein TRADD. ${ }^{18}$

TNF plays a number of roles in cellular signalling, such as induction of $\mathrm{NF}-\kappa \mathrm{B}$ activity in immune cell activation and differentiation. ${ }^{28}$ Through the same receptor TNFR1, TNF can also induce apoptosis. Recent work shows that the function of the proapoptotic activity of TNFR1 DISC is regulated by clAPs. Depletion of clAPs by Smac mimetics sensitised cells 
to apoptosis induction through autocrine TNF. ${ }^{15,16,29}$ Further, it has been shown that overexpression of clAP2 increases the resistance of nasopharyngeal carcinoma to poly I:C-induced apoptosis. ${ }^{30}$ Our results, therefore, strongly suggest that TRIF, when engaged by TLR3, can recruit a similar DISC whose activity is also under the control of clAPs. It is likely that cIAPs in this context are negative regulators of the recruitment of DISC components, especially caspase-8.

In most situations, the function of TRIF is probably induction of type-I IFN rather than induction of apoptosis, especially in myeloid cells. It is unclear how the switch between these two functions is regulated. In macrophages, inhibition of the proteasome permits this switch, presumably because proteasome inhibition blocks the activation of NF- $\kappa \mathrm{B} .{ }^{4}$ clAP2 is an $\mathrm{NF}-\kappa \mathrm{B}$ target $^{31}$ and its upregulation may be relevant in this context. It is not clear why poly I:C induced apoptosis in $\mathrm{HaCaT}$ cells despite the presence of high levels of clAPs. One possibility is that HaCaT cells express different levels of downstream signalling molecules or that poly $\mathrm{I}: \mathrm{C}$ causes a more efficient formation of the TRIF-signalling complex in these cells. Detailed analysis of assembly and signalling will be necessary to understand the requirements of this proapoptotic signalling pathway. TLR3 has been found expressed in many tumour cell lines ${ }^{11,12}$ and was even shown to be overexpressed in renal cell carcinoma as compared with non-malignant kidney. $^{32}$ Stimulation through TLR3 may therefore be one option to be considered for therapeutic induction of apoptosis in tumours, and the mechanism of apoptosis induction and inhibition therefore needs to be studied carefully.

\section{Materials and Methods \\ Cell lines and culture conditions. HaCaT keratinocytes ${ }^{33}$ were cultured in DMEM supplemented with 10\% FCS (PAA) and 1\% (v/v) penicillin/streptomycin (Biochrom, Berlin, Germany). 1205Lu, 451Lu, WM35 and Sbcl2 human melanoma cells representing different stages of tumour progression (1205Lu and 451Lu (from metastatic melanoma), and WM35 and Sbcl2 (radial-growth-phase melanomas) ${ }^{34,35}$ were obtained from Dr Meenhard Herlyn, Wistar Institute, Philadelphia, and cultured in TU2\% melanoma medium containing $80 \%(\mathrm{v} / \mathrm{v})$ MCDB153, 20\% (v/v) Leibovitz's L-15, 2\% (v/v) FCS (Biochrom), $5 \mu \mathrm{g} / \mathrm{ml}$ insulin (bovine), $1.68 \mathrm{mM} \mathrm{CaCl} 2$ and penicillin/streptomycin (Biochrom)). Apoptosis was induced using poly I:C (Sigma, Munich, Germany) at concentrations of $1-50 \mu \mathrm{g} / \mathrm{ml}$ in water. Poly A:U was provided by Dr Stefan Bauer (Phillips-University Marburg). LBW242 was provided by Dr Leigh Zawel (Novartis) and used at concentrations of $1 \mathrm{nM}$ to $50 \mu \mathrm{M}$ in DMSO. All cells were incubated under standard culture conditions $\left(37^{\circ} \mathrm{C}, 5 \% \mathrm{CO}_{2}\right)$.}

Lentiviral constructs and lentiviral infection. For generation of lentiviral Noxa RNAi constructs, shRNA sequence N8 specifically targeting Noxa mRNA was cloned from pSUPER-Noxi8 (a kind gift from Dr Eric Eldering, Department of Experimental Immunology, Academic Medical Center Amsterdam, the Netherlands ${ }^{36}$ ) in the GFP-expressing lentiviral vector pLVTHM (Dr Didier Trono, Lausanne) using restriction enzymes EcoRI/Clal, yielding plasmid pLVAWN8. Lentiviral constructs of shBIM and shScrambled have been described previously ${ }^{37}$. Lentiviral particles were produced by transfecting 293 FT cells (Invitrogen, Karlsruhe, Germany) together with packaging vectors pMD2.G and psPAX2 (Dr Didier Trono, Lausanne). HaCaT keratinocytes were infected with lentivirus carrying either a vector with scrambled shRNA or a vector containing a Bim-specific shRNA fragment or a Noxa-specific shRNA fragment. Cells with lentiviral integration of shScrambled, shBim and shNoxa were sorted for GFP expression by FACS analyses. For overexpression of $\mathrm{mBcl}-2$ in $\mathrm{HaCaT}$ keratinocytes, cells were infected with lentivirus pLVUB-mBcl-2 and selected for puromycin resistance. As control, $\mathrm{HaCaT}$ cells were infected with lentivirus overexpressing the GFP protein (pLVUB-GFP).
Overexpression of CrmA. Human melanoma cell lines 1205Lu and 451Lu were transiently transfected (FuGENE HD; Roche, Mannheim, Germany) with control vector or a Flag-tagged CrmA vector provided by Dr David Vaux, Melbourne. Twenty-four hours later cells were stimulated with $10 \mu \mathrm{M}$ LBW242 plus $50 \mu \mathrm{g} / \mathrm{ml}$ poly I:C for $72 \mathrm{~h}$ and stained for propidium iodide (PI)-positive cells. Transfection efficiency $(50-70 \%)$ was measured by cotransfection using a LacZ expression vector.

Gene knockdown by siRNA. siRNAs were designed according to published guidelines; ${ }^{38} 3^{\prime}$ overhangs were produced as dTdT. Sequences of specific siRNAs are as follows (depicted is the 19-nt portion in the sense strand of the targeted mRNA): Noxa, 5'-AGTCGAGTGTGCTACTCAA-3'; Bid, 5'-CTTGCTCCGTGAT GTCTTT-3'; Puma, 5'-CCGAGATGGAGCCCAATTA-3'; caspase-8, 5'-GCTCTT

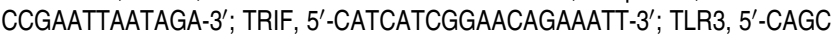
ATCTGTCTTTAATAA-3'; CIAP1, 5'-GGATCCACCTCTAAGAATA-3' and IFNAR, namely IFNAR1335, 5'-GAAACCACTGACTGTATAT- $3^{\prime}$. The sequence of control siRNA is $5^{\prime}$-GCGCAUUCCAGCUUACGUA- $3^{\prime}$. It was designed as a non-silencing control containing a random sequence that does not match within the human and murine genome. A total of 100000 cells were seeded on a six-well plate. Twentyfour hours later $20 \mathrm{nM}$ of siRNA was incubated with $1.25 \mu$ of RNAiMax (Invitrogen) in a total volume of $250 \mu \mathrm{l}$ in OptiMEM (Invitrogen). After $15 \mathrm{~min}$ of incubation at room temperature the siRNA and RNAiMAX mixture was added to the six-well plate giving a total volume of $1.5 \mathrm{ml}$. Stimulation of $\mathrm{HaCaT}$ cells was performed $48 \mathrm{~h}$ post transfection with poly I:C $(50 \mu \mathrm{g} / \mathrm{ml})$ for additional $24 \mathrm{~h}$. For caspase-8-knockdown experiments, melanoma cells were stimulated $48 \mathrm{~h}$ post transfection with poly I:C $(50 \mu \mathrm{g} / \mathrm{ml})$ plus CHX $(2.5 \mu \mathrm{g} / \mathrm{ml}, \mathrm{CHX})$ for additional $24 \mathrm{~h}$. For LBW242/poly I:Cinduced apoptosis, melanoma cells were stimulated $24 \mathrm{~h}$ post transfection with $10 \mu \mathrm{M}$ LBW242 plus poly I:C ( $50 \mu \mathrm{g} / \mathrm{ml})$ for $72 \mathrm{~h}$. When indicated $50 \mu \mathrm{M}$ zVAD-fmk was added at least $20 \mathrm{~min}$ before stimulation.

RNA extraction and quantification by RT-PCR. Total RNA was extracted from cells using the RNeasy mini kit (Qiagen, Hilden, Germany), as described by the manufacturer, and analysed by quantitative RT-PCR. A 1- $\mu \mathrm{g}$ weight of RNA was reverse-transcribed using Expand Reverse Transcriptase (Roche Diagnostics, Mannheim, Germany) and poly(dT) oligonucleotide (Roche) according to the manufacturer's protocol. Quantitative PCR was performed using the LightCycler TagMan Master kit (Roche) together with the Universal ProbeLibrary system (Roche). Relative gene expression was expressed as a ratio of the expression level of the gene of interest to that of hypoxanthine-phosphoribosyl transferase (HPRT) RNA determined in the same sample.

Gene reporter analysis. NF- $\kappa B$ activity was tested using plasmid containing six consecutive NF- $\mathrm{KB}$ consensus sites upstream of a firefly luciferase reporter (provided by Dr H Laumen, Technische Universität, Munich). Cells were transfected in 96-well dishes using FuGENE6 (Roche) along with $50 \mathrm{ng}$ of the reporter plasmid and $50 \mathrm{ng}$ of a Renilla-Luc-expressing plasmid (phRLTK; Promega). Luciferase activity was measured according to the manufacturer's protocol (Promega). Luciferase activity values were normalised to Renilla activity of the same extract.

Western blotting. Cells were extracted in buffer containing 1\% Triton X-100 and protein concentrations were estimated Bradford method. Protein samples were separated on $12.5 \%$ SDS-PAA gels. Antibodies against Mcl-1 (BD Pharmingen, Heidelberg, Germany); Bim; tubulin (both Sigma, Munich, Germany); Noxa (Alexis, Lausen, Switzerland); Puma (Prosci, Poway, CA, USA); Bax (clone 6A7; Upstate Biotechnology, Lake Placid, NY, USA); cytochrome $c$ oxidase subunit-IV (CoxIV; MoBiTec, Goettingen, Germany); caspase-8 (1C12 clone; Cell Signaling, Danvers, MA, USA); GAPDH (Millipore, Schwalbach, Germany); p53 (Cell Signaling); cIAP2; XIAP, mBcl-2 and cFlip (all BD Biosciences, San Jose, CA, USA) and Flag tag (Cell Signaling) were used as suggested by the manufacturers. Bid antibody recognising the cleaved and uncleaved form was provided by Dr David Huang (Walter and Eliza Hall Institute (WEHI)); cIAP1 antibody was provided by Dr David Vaux (La Trobe University, Victoria, Australia). Detection was performed with horseradish peroxidase-conjugated secondary antibodies (specific to mouse, hamster or rat (all Dianova, Hamburg, Germany), or rabbit (Sigma) lgG) and by enhanced chemiluminescence (Amersham Biosciences, Freiburg, Germany). For detection of CIAP1, cIAP2 and XIAP in melanoma cells, whole-cell extracts were prepared before/after incubation with LBW242 $(10 \mu \mathrm{M})$ or $\mathrm{CHX}(2.5 \mu \mathrm{g} / \mathrm{ml})$ for the indicated time points. 
Detection of apoptosis and cell death. To measure cell death, cells were stimulated as indicated, collected and were directly stained by addition of $10 \mathrm{mM} \mathrm{PI}$ and analysed within $1 \mathrm{~h}$ by flow cytometry (FACSCalibur; Becton Dickinson, Heidelberg, Germany); positive-staining cells were considered dead. Staining for annexin-V was performed using FITC-conjugated annexin-V (Invitrogen) in $10 \mathrm{mM}$ HEPES/NaOH (pH 7.4), $140 \mathrm{mM} \mathrm{NaCl}$ and $2.5 \mathrm{mM} \mathrm{CaCl}_{2}$ for $15 \mathrm{~min}$ at room temperature. Annexin-V-positive cells were determined by flow cytometry. Staining for active caspase- 3 was performed with cells fixed for 20 min at room temperature in freshly prepared $4 \%$ formaldehyde in PBS, washed in PBS containing $0.5 \%$ BSA and incubated with rabbit anti-active caspase-3 antibody (Abcam, Cambridge, UK; $1: 500$ ) in staining buffer (PBS/0.5\% BSA/0.5\% saponin) for $30 \mathrm{~min}$. Cells were washed three times with PBS/BSA/saponin and stained with Cy5-conjugated goat anti-rabbit IgG (Dianova, 1:300) secondary antibody for $30 \mathrm{~min}$. Cells were washed and analysed by flow cytometry. For caspase inhibition $50 \mu \mathrm{M}$ zVAD-fmk (Bachem, Bubendorf, Switzerland) was added prior treatment with poly I:C, LBW242, poly I:C plus LBW242 or poly I:C plus CHX, as indicated, to block caspase-dependent apoptosis. Bafilomycin-A (Sigma, $50 \mathrm{nM}$ ) was used to block endosomal ATPase.

Detection of Bax activation. HaCaT cells were harvested post stimulation and stained using activation-specific anti-active Bax antibody (Clone3, 1: 100; BD Biosciences (reference Dewson et al. $\left.{ }^{39}\right)$ ). FITC-conjugated goat anti-mouse IgG ( $1: 300$; Dianova) was used as secondary antibody. Flow cytometry was performed using FACSCalibur.

Subcellular fractionation. Cells were harvested $24 \mathrm{~h}$ post stimulation in mitochondrial buffer and mitochondria were isolated as described earlier. ${ }^{40}$ Subcellular localisation of Bcl-2-family members was analysed by loading equal volumes of the mitochondria-enriched fraction, cytosolic fraction and the pellet fraction after $1 \mathrm{~h}$ ultra-centrifugation (UZ-pellet, $4^{\circ} \mathrm{C}$ at $260000 \times g$ ) on $12.5 \%$ SDS-PAA gels.

\section{Conflict of interest}

The authors declare no conflict of interest.

Acknowledgements. We thank Dr Leigh Zawel (Novartis, Cambridge) for generously providing LBW242. We are grateful to Christian Ploner (Medical University of Innsbruck, Innsbruck, Austria) for providing the shScrambled vector and the shRNA construct directed against Bim. We thank Daria Loos for experimental assistance. This work was supported by grants from the Deutsche Forschungsgemeinschaft to GH (Ha2128) and to RB (GK 1202), and from the Deutsche Krebshilfe to RB (grant 107805).

1. Takeda K, Akira S. Toll-like receptors. Curr Protoc Immunol 2007; Chapter 14 Unit 1412

2. Aliprantis AO, Yang RB, Weiss DS, Godowski $P$, Zychlinsky A. The apoptotic signaling pathway activated by Toll-like receptor-2. EMBO J 2000; 19: 3325-3336.

3. Aliprantis AO, Yang RB, Mark MR, Suggett S, Devaux B, Radolf JD et al. Cell activation and apoptosis by bacterial lipoproteins through toll-like receptor-2. Science 1999; 285 736-739.

4. Ruckdeschel K, Pfaffinger G, Haase R, Sing A, Weighardt H, Hacker G et al. Signaling of apoptosis through TLRs critically involves toll/L-1 receptor domain-containing adapte inducing IFN-beta, but not MyD88, in bacteria-infected murine macrophages. $\mathrm{J}$ Immunol 2004; 173: 3320-3328.

5. Krieg AM. Development of TLR9 agonists for cancer therapy. J Clin Invest 2007; 117: 1184-1194.

6. Hengartner MO. The biochemistry of apoptosis. Nature 2000; 407: 770-776

7. Hacker G, Weber A. BH3-only proteins trigger cytochrome $c$ release, but how? Arch Biochem Biophys 2007; 462: 150-155.

8. Adams JM, Cory S. Bcl-2-regulated apoptosis: mechanism and therapeutic potential. Curr Opin Immunol 2007; 19: 488-496.

9. Sun $Y$, Leaman DW. Involvement of Noxa in cellular apoptotic responses to interferon, double-stranded RNA, and virus infection. J Biol Chem 2005; 280: 15561-15568.

10. Salaun B, Lebecque S, Matikainen S, Rimoldi D, Romero P. Toll-like receptor 3 expressed by melanoma cells as a target for therapy? Clin Cancer Res 2007; 13 (15 Part 1): 4565-4574.

11. Salaun B, Coste I, Rissoan MC, Lebecque SJ, Renno T. TLR3 can directly trigger apoptosis in human cancer cells. J Immunol 2006; 176: 4894-4901.

12. Jiang $Q$, Wei $H$, Tian Z. Poly I:C enhances cycloheximide-induced apoptosis of tumor cells through TLR3 pathway. BMC Cancer 2008; 8: 12
13. Scaffidi C, Fulda S, Srinivasan A, Friesen C, Li F, Tomaselli KJ et al. Two CD95 (APO-1/ Fas) signaling pathways. EMBO J 1998; 17: 1675-1687.

14. Kawai T, Akira S. Antiviral signaling through pattern recognition receptors. J Biochem 2007; 141: 137-145

15. Vince JE, Wong WW, Khan N, Feltham R, Chau D, Ahmed AU et al. IAP antagonists target clAP1 to induce TNFalpha-dependent apoptosis. Cell 2007; 131: 682-693.

16. Varfolomeev E, Blankenship JW, Wayson SM, Fedorova AV, Kayagaki N, Garg P et al. IAP antagonists induce autoubiquitination of C-IAPs, NF-kappaB activation, and TNFalphadependent apoptosis. Cell 2007; 131: 669-681.

17. Meylan E, Burns K, Hofmann K, Blancheteau V, Martinon F, Kelliher M et al. RIP1 is an essential mediator of Toll-like receptor 3-induced NF-kappa B activation. Nat Immunol 2004; 5: 503-507.

18. Ermolaeva MA, Michallet MC, Papadopoulou N, Utermohlen O, Kranidioti K, Kollias G et al. Function of TRADD in tumor necrosis factor receptor 1 signaling and in TRIF-dependent inflammatory responses. Nat Immunol 2008; 9: 1037-1046.

19. Peter ME. The flip side of FLIP. Biochem J 2004; 382 (Part 2): e1-e3.

20. Jiang Z, Mak TW, Sen G, Li X. Toll-like receptor 3-mediated activation of NF-kappaB and IRF3 diverges at Toll-IL-1 receptor domain-containing adapter inducing IFN-beta. Proc Natl Acad Sci USA 2004; 101: 3533-3538

21. Takeda K, Kaisho T, Akira S. Toll-like receptors. Annu Rev Immunol 2003; 21: 335-376.

22. Galluzzi L, Brenner C, Morselli E, Touat Z, Kroemer G. Viral control of mitochondrial apoptosis. PLoS Pathog 2008; 4: e1000018.

23. Kaiser WJ, Offermann MK. Apoptosis induced by the toll-like receptor adaptor TRIF is dependent on its receptor interacting protein homotypic interaction motif. J Immunol 2005; 174: $4942-4952$

24. Han KJ, Su X, Xu LG, Bin LH, Zhang J, Shu HB. Mechanisms of the TRIF-induced interferon-stimulated response element and NF-kappaB activation and apoptosis pathways. J Biol Chem 2004; 279: 15652-15661.

25. Peter ME, Krammer PH. The CD95(APO-1/Fas) DISC and beyond. Cell Death Differ 2003; 10: $26-35$.

26. Hsu H, Xiong J, Goeddel DV. The TNF receptor 1-associated protein TRADD signals cell death and NF-kappa B activation. Cell 1995; 81: 495-504.

27. Cusson-Hermance N, Khurana S, Lee TH, Fitzgerald KA, Kelliher MA. Rip1 mediates the Trif-dependent toll-like receptor 3- and 4-induced NF-\{\{kappal\}B activ. J Biol Chem 2005; 280: 36560-36566.

28. Hacker $\mathrm{H}$, Karin M. Regulation and function of IKK and IKK-related kinases. Sci STKE 2006; 2006: re13.

29. Gaither A, Porter D, Yao Y, Borawski J, Yang G, Donovan J et al. A Smac mimetic rescue screen reveals roles for inhibitor of apoptosis proteins in tumor necrosis factor-alpha signaling. Cancer Res 2007; 67: 11493-11498.

30. Friboulet L, Pioche-Durieu C, Rodriguez S, Valent A, Souquere S, Ripoche H et al. Recurrent overexpression of C-IAP2 in EBV-associated nasopharyngeal carcinomas: critical role in resistance to Toll-like receptor 3-mediated apoptosis. Neoplasia 2008; 10: 1183-1194.

31. Wang CY, Mayo MW, Korneluk RG, Goeddel DV, Baldwin AS, Jr. NF-kappaB antiapoptosis: induction of TRAF1 and TRAF2 and c-IAP1 and C-IAP2 to suppress caspase-8 activation. Science 1998; 281: 1680-1683.

32. Morikawa T, Sugiyama A, Kume H, Ota S, Kashima T, Tomita K et al. Identification of Tolllike receptor 3 as a potential therapeutic target in clear cell renal cell carcinoma. Clin Cancer Res 2007; 13: 5703-5709.

33. Boukamp P, Petrussevska RT, Breitkreutz D, Hornung J, Markham A, Fusenig NE. Normal keratinization in a spontaneously immortalized aneuploid human keratinocyte cell line. J Cell Biol 1988; 106: 761-771.

34. Smalley KS, Contractor R, Haass NK, Kulp AN, Atilla-Gokcumen GE, Williams DS et al. An organometallic protein kinase inhibitor pharmacologically activates p53 and induces apoptosis in human melanoma cells. Cancer Res 2007; 67: 209-217.

35. Satyamoorthy K, Li G, Gerrero MR, Brose MS, Volpe P, Weber BL et al. Constitutive mitogen-activated protein kinase activation in melanoma is mediated by both BRAF mutations and autocrine growth factor stimulation. Cancer Res 2003; 63: 756-759.

36. Alves NL, Derks IA, Berk E, Spijker R, van Lier RA, Eldering E. The Noxa/Mcl-1 axis regulates susceptibility to apoptosis under glucose limitation in dividing T cells. Immunity 2006; 24: 703-716

37. Ploner $\mathrm{C}$, Rainer J, Niederegger H, Eduardoff M, Villunger A, Geley S et al. The BCL2 rheostat in glucocorticoid-induced apoptosis of acute lymphoblastic leukemia. Leukemia 2008; 22: 370-377

38. Ui-Tei K, Naito Y, Takahashi F, Haraguchi T, Ohki-Hamazaki H, Juni A et al. Guidelines for the selection of highly effective siRNA sequences for mammalian and chick RNA interference. Nucleic Acids Res 2004; 32: 936-948.

39. Dewson G, Snowden RT, Almond JB, Dyer MJ, Cohen GM. Conformational change and mitochondrial translocation of Bax accompany proteasome inhibitor-induced apoptosis of chronic lymphocytic leukemic cells. Oncogene 2003; 22: 2643-2654.

40. Eskes R, Desagher S, Antonsson B, Martinou JC. Bid induces the oligomerization and insertion of Bax into the outer mitochondrial membrane. Mol Cell Biol 2000; 20: 929-935. 